\title{
Communicative act development
}

\author{
Marisa Casillas ${ }^{11}$ and Elma H. Hilbrink ${ }^{1,2}$ \\ 1. Max Planck Institute for Psycholinguistics \\ 2. Radboud University
}

How do children learn to map linguistic forms onto their intended meanings? This chapter begins with an introduction to some theoretical and analytical tools used to study communicative acts. It then turns to communicative act development in spoken and signed language acquisition, including both the early scaffolding and production of communicative acts (both non-verbal and verbal) as well as their later links to linguistic development and Theory of Mind. The chapter wraps up by linking research on communicative act development to the acquisition of conversational skills, crosslinguistic and individual differences in communicative experience during development, and human evolution. Along the way, it also poses a few open questions for future research in this domain.

\section{Introduction}

We use language to make things happen-there is a communicative intention at the heart of each utterance that must somehow be encoded (produced) by the speaker and decoded (comprehended) by the addressee. This is not a trivial task, neither for the speaker nor for the addressee; the same communicative intent can be expressed in a number of different ways. For example, "open up", "here comes the choo-choo", "who wants some applesauce?", and "aaa! [with one's mouth posed wide open]" can all be used to elicit the same response: to get a child to open their mouth for a spoonful of food. But these very same utterances mean something quite different in other situations, for example, while at the dentist, watching a train pull into the station, offering options for lunch, or trying a new food. The social and cognitive underpinnings of this flexible mapping between communicative act and linguistic form have long puzzled language scientists and philosophers. How do children manage to break into this system of flexible mappings?

In this chapter we briefly introduce communicative acts, their role in early language development, their application to signed languages, and their more recent extensions to other domains of development (also see Cameron-Faulkner 2014).

\section{Communicative act theory ${ }^{2}$}

Simply speaking, a "communicative act" is the action (or set of actions) that a speaker accomplishes by producing an utterance. Communicative acts include phenomena like requests, invitations, apologies, greetings, and more. The linguistic

\footnotetext{
${ }^{1}$ Contact: marisa.casillas@mpi.nl

${ }^{2}$ We use the term "communicative act" instead of "speech act" throughout this chapter, except when discussing "speech act theory" directly (à la Austin and Searle). Though "speech act" is the more traditional linguistic term, it misses the essential insight that language use is multimodal. "Speech act" is also not naturally extensible to signed languages.
} 
encoding and decoding of a communicative act is closely tied to both (a) the interactants present when the act is communicated and (b) the context in which they find themselves. This idea radically shifts philosophies of meaning away from literal statements about reality, and into the domain of inference and the joint construction of communicative intent. How did this set of ideas come about?

"Speech act" theory gave language researchers a first set of tools with which to study the flexible division of utterance form and utterance meaning. With its roots in the Ordinary Language movement of the early 1900s, speech act theory was introduced by Austin (1962) and further developed by Searle (1969, 1976). Speech act theory introduced the groundbreaking idea that utterances can have different levels of meaning at which actions are accomplished. Traditional speech act theory posits three types of action: linguistic encoding ("locutionary" act), intended significance ("illocutionary" act; Table 1), and effect on the addressee ("perlocutionary" act). In the context of feeding a child, the utterance "here comes the choo-choo!" accomplishes these three types of acts: the locutionary act is in the utterance's realization as a communicative signal (its spoken form), the illocutionary act is a request (i.e., for the child to open his or her mouth), and the perlocutionary act is persuading the child to cooperate in the ongoing activity.

Table 1. Searle's illocutionary act classes

\begin{tabular}{|l|l|l|l|}
\hline \multirow{2}{*}{$\begin{array}{l}\text { Illocutionary } \\
\text { class }\end{array}$} & Definition & \multicolumn{2}{l}{ Examples } \\
\cline { 3 - 4 } Representative & $\begin{array}{l}\text { Commits the speaker to the } \\
\text { truth of the expressed } \\
\text { proposition }\end{array}$ & $\begin{array}{l}\text { I I think that this } \\
\text { stew has little } \\
\text { flavor. }\end{array}$ & "This stew is very \\
bland."
\end{tabular}


The relationship between different levels of action is not always straightforward. For example, perlocutionary acts can arise as unintended consequences of expressing some utterance (e.g., your request for the time reminds me that I am late for a meeting). Some utterances may also entertain multiple perlocutionary meanings. For example, if a mother says, "Is that yours?" the child can take her mother's meaning as a request for information ("no") or as a request to put the object back in its place; the child must infer which response the mother is trying to elicit. In this example, the mother's request is indirect. Similar indirectness can be used with other illocutionary act types. For example, in the exchange "Have you seen Charlie this morning?"- "I just got here, sorry", there is a clear difference between the primary illocutionary act ("I have not seen Charlie") and the secondary one (e.g., "I arrived just now"). In these cases, addressees must decide how to respond, given that multiple communicative acts are being performed simultaneously.

So how do addressees recover a speaker's intended meaning if it is not explicitly encoded in the utterance? If communicative acts take many forms and can even be expressed indirectly, addressees must either rely on convention or infer what the speaker meant from other available evidence. Here, H. P. Grice's Cooperative Principle sheds some light on how addressees might reconstruct intended meanings. Stated as a rule, but intended as a description of human interactional behavior, it is this: "Make your contribution such as is required, at the stage at which it occurs, by the accepted purpose or direction of the talk exchange in which you are engaged" (Grice 1975: 45). In a nutshell, the idea is that if speakers follow this principle and expect their interlocutors to follow it too, they can identify and interpret the non-literal meanings that speakers intend. For example, if you assume that I am cooperative, you should also assume that my response ("I just got here, sorry") is intended to answer your question ("Have you seen Charlie this morning?"), even though it appears to be a non sequitur. Your assumption then encourages you to reason about how my response might be relevant, leading you to the conclusion that I could not usefully answer your question because I just arrived and have not yet seen who is around. ${ }^{3}$ Along similar lines, speakers can "flout" these assumptions in order to express meanings indirectly. For example, if I give you some disappointing news and you reply, "well that's just great", or if you ask me how my new year's resolutions are coming along and I reply, "what awful weather we're having", we can still recover each other's meaning by assuming cooperativity (i.e., "I am unhappy about this disappointing news" and "my new year's resolution has not gone well"). As addressees, we can take these deliberate violations of cooperativity as a signal that something is being said indirectly.

The precise mechanisms by which addressees arrive at inferred meanings are not all well understood. Grice's (1975) theory comes with four "maxims", which are behaviors that addressees can assume speakers will try to observe. They are: Quality (be truthful), Quantity (be informative), Relation (be relevant), and Manner (be clear). In contrast, Sperber and Wilson (1986: 243-254) argue that, among these inferential tools,

\footnotetext{
${ }^{3}$ Note that this interpretation of the question, itself, assumes a non-literal interpretation: you probably don't care if I (in particular) have seen Charlie; "Yes, I have!" would be an insufficient response.
} 
relevance alone is enough to guide addressees' inferences in conversation. Their idea is that the properties of the speaker's utterance and the context of the interaction are enough to put the addressee's inferential process on the right track. Under their theory, the addressee does not need to identify or classify utterances into speech acts to understand their meaning. Both of these approaches bring new questions to bear, including how exactly relevance, or the other maxims, are assessed by addressees, what principles guide ostensive cueing of meaning, and how to resolve competing lines of reasoning.

Rather than asking how addressees "recover" speaker meaning-as if the basis of their understanding solely depended on the speaker's locutionary act-others have focused on how meaning is jointly constructed by speakers and addressees. By definition, interactants are engaged in joint activity, which means that they share not only the relevant context for any given utterance, but also a schema for what to expect and how to contribute to the interaction itself (see H. H. Clark 1996: 29-124 for an introduction; see also Yurovsky 2018). This view conceives of addressees as taking an active role in conversation, and its proponents point to evidence from the construction of referential terms ("What should we call this?"), systems for "repair" in interaction ("Has a problem arisen?", "How should we fix it?"), and verbal and non-verbal resources for conveying information uptake ("How can we signal updates to our mutual understanding?")

In the field of Conversation Analysis (CA), actions in conversation are conceived of as being co-constructed by the participants such that coherent sequences of action emerge as talk unfolds (Sacks, Schegloff, and Jefferson 1974; Schegloff 2007: 1-12). Much of CA focuses on whole sequences of action in conversation and how they are structured ("sequence organization"). Its aim is to discover how each turn within a sequence contributes to the progression of the interaction-in other words, what role does each turn play with respect to the ongoing talk? CA analyses do not typically concern themselves with the encoding and decoding of propositional meaning, but the insights gained by studying sequence organization can inform exactly that: how speakers and addressees leverage local information to create and infer meanings efficiently.

Consider, for example, utterances that require a specific type of response from the addressee. In CA, utterances that require specific responses in the next slot are considered the first half of an "adjacency pair". Adjacency pairs have two parts: the first pair part (FPP; e.g., Question) and the second pair part (SPP; e.g., Answer). First pair parts project a relevant response in the next possible position and must be interpreted within the ongoing sequence. However, the FPP and SPP may be separated by further sub-sequences upon which the realization of the SPP is dependent (e.g., asking a clarification question before giving the answer to a question). The CA conceptualization of adjacency pairs is highly sensitive to the varied relationships between turns that require a response and the responses, repairs, and sub-sequences of action that they elicit. Table 2 below illustrates the richness of CA-style action sequences for the analysis of natural interaction. We place it side-by-side with a mini analysis using Searle's five 
basic illocutionary classes (Table 1 ) to demonstrate connections between the two frameworks, ${ }^{4}$

Table 2. Action sequence from the Providence corpus of spontaneous at-home childcaregiver interaction (Demuth, Culbertson, and Alter 2006; Alex age 2;10.11; ale38:

475). $\mathrm{CHI}=$ child; $\mathrm{MOT}=$ mother.

\begin{tabular}{|c|c|c|c|c|}
\hline Line & Speaker & Utterance & $\begin{array}{l}\text { Searle-style } \\
\text { illocutionary } \\
\text { class (basic) }\end{array}$ & CA-style action sequence \\
\hline 1 & $\mathrm{CHI}$ & this too big & Representative & Complaint (first pair part) \\
\hline 2 & & [no response] & $<$ not applicable $>$ & No response to complaint $t_{\text {Line } 1}$ \\
\hline 3 & $\mathrm{CHI}$ & too big the train & Representative & Pursuit of response to the complaint $t_{\text {Line } 1}$ \\
\hline 4 & & [no response] & $<$ not applicable $>$ & No response to pursuit $t_{\text {Line } 3}$ \\
\hline 5 & $\mathrm{CHI}$ & too big train! & Representative & Upgraded pursuit of complaint $t_{\text {Line } 1}$ \\
\hline 6 & MOT & what honey? & Directive & Repair initiation Line5 $_{1}$ \\
\hline 7 & $\mathrm{CHI}$ & too big train! & Representative & Response to repair initiation Line6 $_{1}$ \\
\hline 8 & MOT & $\begin{array}{l}\text { no, we- it's it's alright } \\
\text { if you push it, it's } \\
\text { when you use the } \\
\text { green one that gets } \\
\text { to be- to be too big }\end{array}$ & Representative & Response to complaint Line1 $_{\text {(second pair part) }}$ \\
\hline 9 & $\mathrm{CHI}$ & I need blue & Representative & Request (initiates a new action sequence) \\
\hline
\end{tabular}

As illustrated in Table 2, CA gives researchers a rich perspective on the interactional meaning of each utterance within a longer sequence. In so doing, it captures both the local meaning of utterances (and silences) as well as the underlying patterns of communicative actions in conversation (Schegloff 2007: 1-12; for more, see Sidnell \& Stivers 2013: 101-280 and Sidnell 2016).

There is still a great amount of work to be done on communicative acts: fundamental questions concerning the nature of communicative acts, their universality, and the cognitive mechanisms underlying them remain largely unanswered (Levinson 2006). We can get fresh insight into these questions by studying how communicative competence develops in children: how do communicative acts shape early language development and vice versa?

\footnotetext{
${ }^{4}$ Note that this is a simplified representation of a Searlean-style analysis; further work has expanded on this initial classification (see, e.g., Blum-Kulka and Olshtain 1984; Holmes 1988; Searle 1975).
} 


\section{Communicative act development}

\subsection{Communication before language}

Children engage in meaningful, communicative interaction from early in infancy. They take turns in vocal exchanges, alternate gaze, and exchange smiles (e.g., Hilbrink, Gattis, and Levinson 2015; Kaye and Fogel 1980; Symons and Moran 1994). The capacity to produce communicative acts emerges during infancy and early childhood, possibly stemming from early playful interactions. Communicative acts are first observed in infants' gestural behaviors during social interactions when they show, give, and point (e.g. Bates, Camaioni, and Volterra 1975; Bruner 1975).

In the early 1970 s researchers started to focus on children's communicative language use as a way to understand how language is acquired. Bruner (1975), Bates and colleagues (1975), and Dore (1974) were among the first to emphasize the importance of early pragmatic development for language acquisition, focusing much of their work on infant play. Highly predictable routines, such as peek-a-boo, give-and-take, rolling a ball back and forth, and care routines (e.g., diaper changing) provide a rich context for infants to learn about interactional structure and communicative skills. In these routines, infants practice taking turns and begin to segment the roles of different components from the ongoing activity: the agents, actions, objects, recipients, and their respective positions in the action sequence. Building on these familiar action sequences, children can manageably test out their conversational skills by anticipating the next action in the sequence and expertly preparing their response (e.g., holding back the response laugh in peek-a-boo). Role reversal games such as passing a ball back and forth also allow infants to learn that they can be recipients or agents, and what each role encompasses (Bruner 1975).

By focusing on the development of communicative skills, researchers can assess continuity in children's linguistic development from infancy to later childhood; they can trace language skills back to pre-linguistic behavior. One of the clearest demonstrations of this continuity in communicative development is Bates and colleagues' (1975) quasilongitudinal study, which assessed the emergence of intentional communication prior to productive language use. Their analysis focused on children's early communicative acts. Working within a traditional speech act theory framework (see Section 2), they highlighted three children's early use of "proto-imperatives" (defined as using the adult as a way of getting a desired object) and "proto-declaratives" (defined as using an object as a way of attracting an adult's attention). They charted the development of communicative act understanding and communicative act production in these children from age 2 months to 16 months and found that the first intentional communicative acts emerged around 10 months of age.

In the first few months of life, infants produce cries, smiles, and vocalizations that elicit responses from their caregivers even though the infants themselves are not yet aware of the communicative meaning of these behaviors. Bates and colleagues (1975) classified these early communicative behaviors as perlocutionary communication in that they often effect a desired change in the infant's environment, for example the infant is being picked up, entertained, fed, or attended to in some other way. Similarly, when 
infants start to reach for objects, they do so without realizing that the object could be used to obtain attention or that the adult could be used to obtain an object. Even though these behaviors are not yet intentional communicative acts, they do provide the infant with important experience: these early behaviors allow the infant to discover the physical and social contingencies that are the bedrock of adult communication. In their seminal study, Rovee and Rovee (1969) showed that infants as young as 2-3 months learn very quickly that when a mobile hanging above their crib is attached to their leg by a string, the mobile will move when they kick their legs. Similarly, Murray and Trevarthen (1985) found that infants look less at their mothers and smile less frequently when they see a recording of an earlier interaction with their mothers compared when they are experiencing a live interaction with her. These findings were some of the first to show that infants detect contingencies in the physical and social world from early on. And although many of these early contingent actions are initially expressed as means-end relationships (e.g., crying results in being picked up, or smiling elicits smiling back from the caregiver), they gradually develop into more sophisticated means-end realizations, such as pulling a cloth with a toy on it to obtain the toy. This in turn develops into the use of proto-imperatives, for example, looking fixedly at an adult's face while reaching for a toy, which is what Bates and colleagues (1975) found to emerge around 10 months of age.

Similar to the transition from early means-end relationships to proto-imperatives, continuity is also observed in the development of proto-declaratives. First, infants start with "showing off" (repeating behavior that has previously attracted attention). Then they progress to showing objects, then giving objects, and finally pointing to objects (Bates, Camaioni, and Volterra 1975; Cameron-Faulkner et al. 2015). Showing and giving objects are the first behaviors classified as intentional declaratives and are reported to emerge around 10 months of age-around the same time proto-imperatives appear (Bates, Camaioni, and Volterra 1975). Notably then, many of children's early communicative acts are produced through gestural rather than linguistic means.

\subsection{Transitioning to communication with language}

Infants' non-verbal behavior plays an important role in early communication and is a fundamental piece of the puzzle in linking pre-linguistic behavior to later linguistic development. Infants typically use gestures before they begin to speak, but even before infants start using gestures, they produce communicative actions (e.g., bringing an empty spoon to the mouth), that correspond to the meanings of later gestures, such as bringing a hand to the mouth. These acts eventually lead to their corresponding words, such as "eat" or "food" (Capirci et al. 2005). Furthermore, children use gestures to refer to objects before producing the word for those same objects (Iverson and GoldinMeadow 2005). The findings of Capirci and colleagues suggest that gestures support early word use: infants start using many words within gesture-word combinations and then later transition to using the words without gesture. In another study, Capirci and colleagues (1996) showed that in one-element utterances (i.e., a single word or single gesture) the use of gesture declines from 16 months to 20 months of age. At the same time, in two-element utterances gesture continued to be a frequent part of the 
utterances. Furthermore, the number of gestures and gesture-word combinations at 16 months of age predicted the amount of total vocal production (i.e., single-, two-, and multi-word utterances with or without gestures). Together, both studies provide evidence that gesture supports early word use and continues to be produced even after children begin to use more words. Butterworth and Morissette (1996) also found that children who pointed earlier used more gestures and more often recognized animal sounds at 14 months. Similarly, Carpenter and colleagues (1998) found that children who started using communicative gestures earlier also used referential language terms earlier, i.e., words for concrete actions or objects (see also Colonnesi et al. 2010 for a meta-analysis on the relation between pointing and language development).

Soon after children produce their first words, the number of communicative acts they produce per minute rapidly increases (Snow et al. 1996). Snow and colleagues (1996) conducted the most comprehensive longitudinal study on communicative act development to date. They longitudinally tracked the communicative act development of 52 children at 14, 20, and 32 months of age using the INCA-A. The INCA-A coding system was developed by Ninio and colleagues to study the development of communicative acts in a comprehensive and theoretically sound way (see Ninio and Wheeler 1984, 1986; Ninio et al. 1994). Grounded in traditional speech act theory, sociology, and Conversation Analysis, the INCA-A differentiates between two levels of communicative intent: (a) the interchange level, one or more rounds of talk with the same interactive function, and (b) the utterance/communicative act level, the intent of the utterance from the speaker's perspective. One of the major advantages of the INCA system is that it was specifically designed to code communicative act development across a wide age range and therefore allows researchers to assess continuity in communicative act development. Using this system, Snow and colleagues (1996) demonstrated that infants' pragmatic flexibility (the number of different interchangecommunicative act combinations) increased with age, and that infants' communicative act development was related to their productive language use. The first emerging communicative interchanges at 14 months were focused on the infant's immediate environment, such as communicative acts directing the addressee's attention, negotiating immediate activities, and discussing joint focuses. By the age of 32 months, infants' communicative interchanges included objects and events that are not observable, such as recent events and the addressee's thoughts and feelings. At the level of communicative acts, Snow and colleagues found that transferring objects, repeating utterances, answering wh-questions, and requesting/proposing were among the first types of communicative acts to emerge.

\subsection{Understanding others' intentions}

To effectively participate in conversation, children must be able to infer others' communicative intentions. As described above, there are several theoretical accounts describing how addressees might infer speaker intention, of which Grice's has been the most prominent (Grice 1975). Grice's account of intentional communication is built on the assumption that addressees can reason about others' thoughts and beliefs, in other words, that they have a Theory of Mind (Premack and Woodruff 1978). Without any 
simplifications, a Gricean account of intentional communication would require that children understand that (a) speakers intend to achieve a goal (which is likely shared with the addressee), and (b) speakers expect addressees to recognize what the speaker intends and not just what they say, both which may be quite complex for children (e.g., Moore 2014).

However, there is a wealth of evidence suggesting that infants are able to infer intentions from early on. A wide variety of abilities related to intention understanding emerge in the second half of children's first year, before first words appear. These abilities include goal understanding, joint attention skills, and more advanced intention reading. For example, at 9 months infants already distinguish between someone who is unwilling to hand them a toy (teasing) and someone who is unable to give them a toy because she accidentally dropped it (Behne et al. 2005). Similarly, 13- and 14-montholds selectively imitate goal-directed and intentional actions and ignore actions that are not considered related to the goal or are considered accidental (Sakkalou et al. 2013). Furthermore, 14-month-olds recognize other people's goals and, if something goes awry, children spontaneously help those people reach their goals (Warneken and Tomasello 2007). A series of studies by Woodward suggest that goal understanding (in this case, reaching for an object) emerges between 6 and 9 months of age. She showed that when an actor repeatedly reaches for one of two toys (e.g., a teddy bear instead of a ball), children expect the actor to continue reaching for that same toy and express surprise when the actor reaches for the other toy instead, even if the location of the toys changes. Woodward suggests that infants interpret these reaching actions in a goaldirected manner, i.e., that the actor's goal was to obtain a specific object (Woodward 1998, 1999).

Traditionally, children's belief understanding has been tested with false belief tasks such as the Sally-Ann task (Baron-Cohen, Leslie, and Frith 1985). In this task, children listen or watch a story about Sally and Ann. In the story, Sally puts a marble in a basket and leaves. When Sally is gone, Ann appears and hides the marble in a box. When Sally returns, the children are asked which of the two containers they think Sally will look in. If children understand that people can have beliefs that diverge from reality ("false beliefs") they will say that Sally thinks the marble is in the basket. Children generally pass this task around the age of 4 years. But more recent work shows that infants can attribute false beliefs to others from the beginning of the second year of life when they are tested with non-verbal tasks (see Baillargeon, Scott, and He 2010 for a review).

Children's early intention understanding has been linked to the ability to share attention with others, specifically to the ability to engage in triadic interaction which involves sharing attention with another person about a third entity (e.g., a toy). This type of triadic interaction is known as joint attention. The ability to engage in joint attention emerges around 9-12 months of age and typically requires the child to be aware of their interlocutor as an intentional agent (Tomasello 1995). Joint attention abilities, such as pointing and gaze following appear to be an important aspect of language development (e.g., Carpenter et al. 1998; Morales et al. 2000; Mundy et al. 2007; Scott et al. 2013). Carpenter and colleagues, for example, conducted a longitudinal study on the 
relationship between joint attention, imitative learning, imperative and declarative gestures, and language in development. They demonstrated that joint attention abilities and communicative gestures, such as gaze following and pointing, were related to the emergence of referential language (Carpenter et al. 1998). Furthermore, Carpenter and colleagues observed that joint engagement (sharing attention about a third entity, like a toy) consistently preceded the emergence of communicative gestures, which in turn consistently preceded the emergence of referential language.

Shortly after learning to engage in triadic interactions, infants become more active participants during coordinated joint interactions (Tomasello et al. 2005, see also Bakeman and Adamson 1984 for the development of various engagement states). This more active involvement has been shown to be important for acquiring language. Looking at infants' involvement, Scott and colleagues (2013) distinguished between two aspects of joint attention: mothers following-in into what the infant was attending to and infants following-in into what the mothers encouraged them to look at. Both aspects of joint attention predicted productive vocabulary size between 14 and 18 months, but infant follow-in was a stronger predictor than maternal follow-in. Infants who more often followed-in to their mother's locus of attention added new vocabulary words faster than infants who did not follow-in as often.

Even though infants' ability to infer intentions is now well-documented, how exactly they manage to understand and produce communicative intent is still an open question. The Natural Pedagogy account (Csibra and Gergely 2009; Csibra 2010) suggests that infants are born with the ability to recognize ostensive communicative cues-cues that indicate that something is being communicated. These cues include infant-directed speech, eye contact, and contingent turn taking (Csibra 2010). For example, Senju and Csibra (2008) demonstrated that, when viewing two objects, 6.5month-olds look significantly more toward an object looked at by an actor, but only if the actor first makes eye contact with the child or speaks in a child-directed manner before turning her head. Moore, Liebal, and Tomasello (2013) suggest that ostensive cues may be used to establish communicative interaction but not to maintain communicative interaction; they found that 3-year-olds inferred communicative intentions regardless of whether ostensive cues were used. In their study, cooperative communication was already established during a warm-up phase, and therefore the children might not have needed ostensive signals in the test phase. In sum, children can infer intentions from infancy onwards and can use ostensive cues such as eye contact and child-directed speech to recognize that something is being communicated to them. But the exact function of these ostensive cues for language learning and communication is still unclear; for example, infants might not need ostensive cues to infer meaning and make responses in some interactional contexts (Shatz 1978a, 1978b).

According to Shatz, children can often get by during interaction without directly inferring others' communicative intentions (Shatz 1978a, 1978b). Shatz proposed that young children infer how they should respond to prompts from their caregivers by integrating superficial cues from the utterance with their knowledge about the affordances of objects currently in joint attention (see also E. V. Clark 1973). Along these lines, Shatz argues that children develop a strong bias to respond to verbal prompts with 
some kind of action-children can respond relevantly without needing to understand the prompt. So, when asked to "shut the door", the word "door" can be enough for children to infer what they should do (Shatz 1978a; E. V. Clark 2009: 21-50). In other words, young children may find ways to respond appropriately in interaction without needing to first infer the speaker's meaning, at least in the way that we assume adults typically do. In many cases they then receive feedback about the appropriateness of their response (Shatz 1978b). This strategy gives children an efficient and effective avenue into nonroutine interactions, but it also breaks down quite easily-for example, if the parent asks, "Where's the door?" and the child closes it in response.

As mentioned in Section 2, some analytical frameworks emphasize that meaning is constructed jointly by the interactants (e.g., H. H. Clark 1996; Sacks, Schegloff, and Jefferson 1974). That means that participants in interaction have partial access to other participants' goals through their own knowledge about the joint goals, history, and current context of the interaction (i.e., their "common ground"). But, in order to benefit from their participation, children need to track what is in common ground with their interactants and what is not. O'Neill (1996) found that 2-year-olds take into account what an adult knows when requesting help from that adult. Toddlers asked for help by gesturing towards the location where a desired object was hidden significantly more often when the adult had not witnessed the hiding event compared to when the adult had witnessed the hiding. Moll and colleagues (2008) demonstrated that even 14-month-olds keep track of the experiences they share with others and act accordingly with their experience when continuing with the interaction. In their study, children looked at several objects with an experimenter, but only experienced shared excitement about one of the objects. When the experimenter later asked infants to hand them an object (neutrally referred to as "it"), infants picked the object about which they and the experimenter had shared excitement previously. Crucially, when someone other than the experimenter asked infants to hand them an object, infants did not show this preference. Thus, infants kept track of what they had shared with whom, and in what way.

\subsection{Summary}

Infants begin to develop skills for understanding and producing communicative acts early in infancy. Highly routinized interactions play a foundational role in this development (e.g., Bruner 1975). Around the same age at which infants start to first understand intentions, triadic joint attention behaviors also emerge (e.g., Carpenter, et al. 1998; Tomasello 1995), at which point infants also begin to produce protoimperatives and proto-declaratives (e.g., Bates, Camaioni, and Volterra 1975; CameronFaulkner et al. 2015; Tomasello 1995). The early gestural communicative behaviors that accompany proto-imperatives and proto-declaratives, such as pointing, influence children's later linguistic development. In inferring other speakers' intentions, infants can use ostensive cues, common ground, and the affordances of the current context, all of which helps them respond appropriately. This developmental trajectory demonstrates the close relationship between intention understanding, communicative act development, and language acquisition. Even though we have learned much about the development of communicative acts in prior research, important questions about the precise cognitive 
mechanisms for understanding and producing communicative intentions (and how they develop) remain largely unanswered.

\section{Communicative acts in signed languages}

So far we have focused on the acquisition of communicative acts in children acquiring spoken languages, but now we turn briefly to how children begin to use and understand communicative acts in signed languages. Although there has been much less research on the acquisition of communicative acts for signing children, the nature of early communication-its tight connection to the interactional context and its reliance on non-linguistic actions-makes it likely that early communicative act development in signing children is generally similar to what has been documented for speaking children. Crucially, however, the affordances of communication in the visual modality may affect the format of children's early communication with their caregivers. In what follows, we briefly review what is similar and what is different in the two settings.

\subsection{Acquiring a signed language}

Before we summarize recent work on this topic, it is useful to give some background on the children and parents who are generally focused on in the studies we mention. ${ }^{5}$ One of the more striking facts to take into account in thinking about communicative act development in this population is that $90-95 \%$ of deaf children are born to hearing parents, most of whom have had no previous training with a signed language (Mitchell and Karchmer 2004). Once a child is diagnosed with severe hearing loss (which itself may take some time to recognize), most parents arrange for their children to get cochlear implants or hearing aids. However, the pre-implantation period can last for months or even years. During this period, typically developing hearing children develop many crucial skills on the basis of their social and verbal interactions with their caregivers including: triadic joint attention, familiarity with games and routines, and proto-imperatives and proto-declaratives (Section 3). What happens during this same period for families with deaf children?

Hearing parents of deaf children often do much to adapt their interactional style; they are more likely to use mixed modalities (speech and gesture) in interaction, they move objects and gestures into children's visual fields, use points and body-taps to gain attention, and even use more exaggerated gestures than deaf parents of deaf children (Depowski et al. 2015; Koester, Brooks, and Karkowski 1998; Waxman and Spencer 1997). However, hearing parents still lack fluency in the use of non-spoken communication, which may affect the overall quality of the input and, thereby, children's interest in interactional engagement (Depowski et al. 2015). For example, deaf children of hearing parents engage in less sustained interactions than deaf children of deaf

\footnotetext{
${ }^{5}$ The work on early communicative development in signing children is primarily limited to Western Deaf communities, where signers are the vast minority and where communities have historically built up around organized education (e.g., schools for the deaf). However, there is a whole other world of signing-smaller communities with higher (often genetic) incidence of deafness - that gives a very different picture than the one we paint here. For more information, see Zeshan and de Vos (2012).
} 
parents (Gale and Schick 2009) and spend less time overall in joint attention (Spencer 2000; Prezbindowski, Adamson, and Lederberg 1998). Parents who can sign fluently have the ability to shift into child-directed signing when engaging their children in interaction. In child-directed signing they use longer, bigger, more repetitive, and more accessible signs to keep the child's attention, a communicative style that is perhaps more difficult for parents who are not fluent signers (Holzrichter and Meier 2000; Swisher 2000; Masataka 2000). For these reasons, much of the work on children's early communicative development in deaf and signing families has centered on differences that arise between deaf children with deaf parents and deaf children with hearing parents.

\subsection{Communicative act development in deaf and signing families}

Signing children's early use of proto-declaratives, proto-imperatives, and the transition of these communicative acts from early gesture to early symbolic communication appear developmentally quite similar to what is found for speaking children. One study of 14 deaf children of hearing parents elicited proto-imperatives and proto-declaratives between ages 18 and 30 months. They found that deictic gestures (e.g., pointing) emerged first and continued to be used frequently with development, but also that the frequency and diversity of communicative acts, plus their combination with gaze increased with age (Lichtert and Loncke 2006). The timing of this trajectory appears slightly delayed compared to what has been documented for hearing children of hearing parents (Section 3). In contrast, some have proposed that children acquiring signed languages from birth (typically deaf children with deaf parents) will make the transition between gesture and early symbolic communication earlier than children acquiring spoken languages. Goodwyn and Acredolo (1993) tested this hypothesis by training hearing parents to systematically use gesture during their interactions with their children. They then recorded children's use of symbolic communicative acts in both the gestural and spoken modality, finding that there is a very small ( $\sim$ month) but consistent advantage for symbolic communication in the gestural modality (also see Morgenstern et al. 2010). The authors conclude that, for children exposed to interaction rich in spoken or visual signals, the shift in early communicative behavior from gesture to symbolic communication is approximately similar, perhaps even gated by other cognitive developments that enable symbolic representation (see, e.g., Volterra and Caselli 1985).

One place where we can expect differences between signing and speaking children's early communication is during episodes of joint attention. When triadic joint attentional episodes (e.g., book reading or toy play) take place purely in the visual modality, children and parents need to engage in an additional set of behaviors to make sure that their attention stays coordinated. For example, during book reading, hearing children can listen to speech and look at the shared object (the book) simultaneously. Signing children (and parents) need adapt their behavior so that the linguistic information (the signs) and the object information (book) are both available to the child, for example, by signing on the book or frequently switching gaze between different targets (Lieberman, Hatrak, and Mayberry 2014; Chasin and Harris 2008). Sign-acquiring children appear to master the basics of this attentional control by age two; during 
episodes of book reading, they look back at their caregiver more than a third of the time and make an average of 15-16 gaze switches per minute, whereas hearing children of hearing parents hardly look back at their caregiver at all in the same context $(1 \%$ of the time, and one gaze switch per minute; Lieberman, Hatrak, and Mayberry 2014).

Even though children master the basics of this attentional control by age two, their gaze switching and their sensitivity to more subtle attention-getting cues increases with age. Increased sensitivity to these cues is a critical development, allowing children to effectively coordinate their use of communicative acts with others during complex interactions. Notably, signing caregivers too have to adapt their language use to ensure that their communicative behaviors are coordinated with the child. Caregivers begin with explicit attention getters (e.g., body taps), but these become less frequent as children get older and, instead, caregivers expect children to understand more subtle behaviors, such as looking, as a bid for mutual gaze and simply beginning a turn at talk within conventional signing space (Harris et al. 1989; Baker and van den Bogaerde 1996; Waxman and Spencer 1997). So, in addition to learning how to use and understand early communicative acts, children acquiring signed languages must also learn early on how to shape their attention such that they can coordinate their communicative acts with others and still track the objects and events currently being talked about.

\subsection{Signed language acquisition and Theory of Mind}

Finally, much work on early communicative development in deaf and signing children has focused on the acquisition of Theory of Mind. As discussed above, the ability to think about other people's thoughts and beliefs is probably crucial for our ability to infer others' communicative intentions. Collectively, this research has established that deaf children from deaf families show parallel Theory of Mind development to hearing children from hearing families, but that deaf children from hearing families show delayed development with both language-based and non-language-based measures of Theory of Mind (Schick et al. 2007; Moeller and Schick 2006). The same pattern shows even with implicit non-verbal measures of Theory of Mind in infancy (Meristo et al. 2012). These findings suggest that, even before children begin to use and understand words, they benefit from the input they get in rich, linguistically fluent interactions with their caregivers (Meristo et al. 2012; Schick et al. 2007).

In fact, the same pattern can hold for adults who have limited experience with Theory of Mind words (e.g., "think" and "believe") and syntax (subordinate clauses, i.e., "She thinks that X"). For example, Nicaraguan Sign Language (NSL), which began in the 1970s, took some time to develop Theory of Mind signs, such as "believe". Early signers of NSL grew up without using these terms while later signers used them from the start. Pyers and Senghas (2009) found that the signers who did not grow up with these signs failed a non-linguistic test of Theory of Mind, while signers who did grow up with them performed well. Interestingly, when they tested these participants again two years later-when there had been much more social interaction between the earlier and later signer generations - they found that the earlier generation used more Theory of Mind signs and also now could pass the test. Their results suggest that the ability to talk about unobserved mental events helps participants to conceive of the mind-states of others. 
However, as fully functional members of the NSL community, the early-generation participants in their study must also have had some mechanisms for thinking about others' mental states (e.g., for inferring the meaning of communicative acts) before learning these explicit Theory of Mind terms. The results therefore bring us back to thinking about the precise way in which Theory of Mind links to everyday attributions of communicative intent. It may well be that adults, as well as children, in both signed and spoken interaction, have a whole range of mechanisms for understanding the intentions behind communicative acts, some of which are identified above.

\section{Links to other developmental domains}

As we have seen, communicative acts are produced and understood in multiple modalities, they often rely on cultural and linguistic knowledge, and they require participants to closely track the ongoing interactive context. For these reasons and more, many other areas of language study naturally connect to communicative acts. Language researchers have investigated communicative acts in a diverse set of domains, including the acquisition of conversational skills, the role of communicative acts in human evolution, and cross-linguistic and individual differences in communicative experience during development.

Much of the work focusing on how children acquire conversational skills has addressed the development of communicative acts. Conversations are made up of sequences of joint action. But how do children get into these complex sequences? As mentioned above, highly predictable caregiver-infant interactional routines (e.g., peek-aboo) establish interactional templates (Bruner 1975). Even in the initial stages of infancy, there are highly structured non-verbal routines that may serve as initial templates for children trying to break into interaction (Reddy et al. 2013; Takada 2011). These early action templates help children break first ground in learning turn-taking rules and other conversational norms, but they are also tightly connected to the communicative acts that define each action in the routine.

Experimental work on children's predictions about conversational turn taking has also yielded evidence that utterances requiring responses could have a special place in pragmatic development. Starting around age two, children watching videos of dialogue spontaneously anticipate upcoming responses after hearing questions, but not after nonquestions (Casillas and Frank 2017; Lammertink et al. 2015). The linguistic and nonlinguistic cues children use to recognize questions in real-time conversation are not yet well understood, but it is clear that between age two and three, children begin to (a) understand that questions call for an immediate response and (b) seek them out to anticipate upcoming response needs, even when they are a third-party participant (Lammertink et al. 2015). Whether or not children make the same kinds of predictions for other types of response-encouraging utterances (e.g., greetings, compliments, complaints) still needs to be tested.

Children's early experience with response-requiring utterances varies across linguistic communities. Even within communities, response-requiring utterances vary in frequency and type as children grow older. Research on early language development in Western settings indicates that questions, especially "test" questions (e.g., "What does a 
kitty say?"), tag questions (“That was fun, huh?"), and repair questions (e.g., "You want more what?") are frequent in caregiver-child interaction, even in early infancy when there is no chance that the child can give a true response (Snow 1977). As children get older, caregivers ask more "real" questions (e.g., "What happened?"; Fitneva 2012; Casillas, Bobb \& E. V. Clark 2016)-a developmentally critical distinction for communicative acts that is not clearly predicted in Gricean or CA theoretical accounts. That said, early "childfriendly" question-asking is not at all universal. In many cultures, caregivers encourage children to adapt to the social interactions in their environment and minimize children's expectations that their social partners will adopt a child-centric perspective (see Lieven 1994 and Gaskins 2006 for summaries). In these communities, there is little reason for "test" and "tag" questions unless they specifically relate to the topic at hand. Even within Western cultures, researchers have found variation in the amount and style of communication that children encounter, including the prevalence of questions (e.g., Hart and Risley 1995; Fernald, Marchman, and Weisleder 2013; Weisleder and Fernald 2013) and have linked these differences in linguistic (and pragmatic) experience to speed of word recognition and vocabulary development.

Within single communities, individual children also show substantial variation in their use of early communicative acts. In one longitudinal study of 95 children, Mundy and colleagues (2007) looked at two communicative acts relating to triadic joint attention: initiating and responding to bids for joint attention. They found that children who responded to joint attention more often at 12 months and children who initiated joint attention more often at 18 months ended up with larger receptive (comprehension) vocabularies at 24 months, even when they accounted for differences in children's general cognitive development. Mundy and colleagues also found that some individual differences in joint attention were stable over development; for example, children who were less likely than average to make eye contact while initiating joint attention at 9 months also made lower-than-average eye contact when initiating joint attention at 18 months. Building on these results, the researchers argue that the impact of different communicative acts surrounding joint attentional events (initiating and responding) differs, depending on the child's stage of development. This result adds both individual variation and developmental timing to the list of features that shape the relationship between communicative act development and linguistic development.

These findings on individual differences in question-asking and joint attention lead us to ask just how variable children are in their communicative act development. The sum of prior work suggests that while children learn to leverage some communicative acts (e.g., requests for response, repairing misunderstandings, bids for joint attention) early on, there is immense variability across communities and individuals in the frequency and use of other communicative acts. We therefore expect variable trajectories for communicative act development across children and a complex relationship between communicative act development and language learning.

Most developmental work on communicative acts has focused on the first few years of life, but some aspects of communicative act development are not mastered until later childhood, or even until adolescence. Before age eight, children often respond in conversation in ways that adults find to be pragmatically "inappropriate" under the 
circumstances (Bishop and Adams 1989). And while children respond to requests for repair soon after they begin speaking (Tomasello, Conti-Ramsden, and Ewert 1990; Forrester 2008), their responses are usually limited to self-repetition (Brinton et al. 1986). Sometimes children receive several repair requests in a row (e.g., "huh?""what?"- -I didn't understand that"). Until age five, they have a few strategies for adapting their responses when faced with these repeated repair requests. But, between ages five and seven, children start to consistently add new information to their responses after they receive repeated requests for clarification. Only at age nine so they begin to repair serious breakdowns by backtracking to the original point of misunderstanding (Brinton et al. 1986).

Similarly, although children begin to make requests in infancy, they do not master persuasion or politeness for quite some time; both skills are complex, requiring children to mask requests as indirect communicative acts (Bates 1976; Axia and Baroni 1985). In experimental settings, five- and six-year-olds can mask their requests by making them indirect, but they cannot yet alter their requests flexibly when dealing with resistance from an adult (Axia and Baroni 1985). Request alteration following resistance only happens at age seven and up (Axia and Baroni 1985). In spontaneous interactionwhen children are self-motivated to make successful requests (e.g., getting their caregiver to buy them a toy) - their persuasive tactics look more sophisticated. Under these circumstances five- and six-year-olds take their caregiver's objections into account in their bargaining and they increase their politeness when making more substantial requests ("But I must have all the kinds of Legos!"; Ervin-Tripp, Guo, and Lampert 1990; Axia 1996). By age eight, children even begin to reframe their toy-purchase proposals in more cooperative terms ("How much does this one cost? A lot, huh? And this one?"; Axia 1996). At this stage, the strategies for executing a successful request go far beyond masking a single utterance and instead become entire sequences of action.

As far as we know, humans are the only species using these kinds of complex conventions to encode communicative intentions. In fact, humans may be the only species to spontaneously aim to share joint attention between individuals. Hurford (2016) argues that two developments-the social motivation to communicate and the ability to infer others' points of view-form the bedrock of our species-specific ability to read others' cooperative intentions and encode our own communicative intentions in a wide array of linguistic formats. Our great ape relatives, such as chimpanzees, bonobos, and orangutans use alert calls and some non-verbal sequences of communicative acts (e.g., Rossano and Liebal 2014; Rossano 2013). But these are typically limited to direct actions on either the speaker or the addressee (e.g., not about a third object) and are therefore limited in range compared to the full domain of human speaker meanings (Hurford 2016; Tomasello 2010: 319-346). That said, recent work comparing orangutans to human infants argues that some social action sequences, such as those involved in food-sharing, pre-date humans and are found in several primate species (Rossano and Liebal 2014). Future comparative work will be crucial for revealing the prehistoric roots of modern human communicative acts. 


\section{Concluding remarks}

To use language with others, we must be able to produce and comprehend communicative acts. In this chapter, we have reviewed some basic analytical frameworks for thinking about communicative acts (Section 2), described research on the early development of communicative acts in spoken and signing families (Sections 3 and 4), and touched upon several links between early communicative act development and other domains, including the evolutionary origins of language (Section 5). Generally speaking, children show an early competence for communicative acts. The emergence of communicative acts is marked by a reliance on gesture, interactional routines, and early insights about their interlocutor's perspective and experience; much the same for children acquiring spoken and signed languages. There is still much to be done in pinpointing the precise mechanisms behind early communicative development. An important avenue for future work will be to explore the ways in which these mechanisms adapt to differences in early interactional experience, for example how communicative act development proceeds in families and language communities where child-centric joint-attention and ostensive communicative cues are infrequent (Gaskins 2006). This chapter only scratches the surface in illustrating the multi-method approach that can be taken to studying children's developing communicative skills: between speech act theory, Grice, common ground, relevance theory, and CA, researchers have a diverse set of tools at hand with which to gain insight about children's natural interactions. Experimental research also has an enormous role to play in helping us tap into children's tacit knowledge about interaction and to help elicit behaviors that are otherwise rare in everyday interaction. As we have seen, early communication act development is closely intertwined with linguistic and social development. Future work needs to explicitly address the connection between these three domains so that we can better understand communicative development as a whole.

\section{Acknowledgements}

This project was supported by an ERC Advanced Grant (269484 INTERACT) to Stephen C. Levinson and an NWO Veni Innovational Research Scheme grant (275-89033) to MC.

\section{References}

Austin, John L. 1962. How to do things with words. Oxford: Oxford University Press.

Axia, Giovanna. 1996. How to persuade mum to buy a toy. First Language 16(48). 301-317.

Axia, Giovanna \& Maria R. Baroni. 1985. Linguistic politeness at different age levels. Child Development 56(4). 918-927.

Baillargeon, Renée, Rose M. Scott \& Zijing He. 2010. False-belief understanding in infants. Trends in Cognitive Sciences 14(3). 110-118.

Bakeman, Roger \& Lauren B. Adamson. 1984. Coordinating attention to people and objects in mother-infant and peer-infant interaction. Child Development 55(4). 1278-1289. 
Baker, Anne E. \& Beppie van den Bogaerde. 1996. Language input and attentional behaviour. In Carolyn E. Johnson \& John H. V. Gilbert (eds.), Children's language (Vol. 9), 209-217. Mahwah, NJ: Erlbaum.

Baron-Cohen, Simon, Alan M. Leslie \& Ute Frith. 1985. Does the autistic child have a "theory of mind"? Cognition 21(1). 37-46.

Bates, Elizabeth. 1976. Acquisition of polite forms: Longitudinal evidence. In Elizabeth Bates (ed.), Language and context: The acquisition of pragmatics, 245-294. New York: Academic Press.

Bates, Elizabeth, Luigia Camaioni \& Virginia Volterra. 1975. The acquisition of performatives prior to speech. The Merrill-Palmer Quarterly 21(3). 205-226.

Behne, Tanya, Malinda Carpenter, Josep Call \& Michael Tomasello. 2005. Unwilling versus unable: Infants' understanding of intentional action. Developmental Psychology 41(2). 328-337.

Bishop, Dorothy V. \& Catherine Adams. 1989. Conversational characteristics of children with semantic- pragmatic disorder II: What features lead to a judgement of inappropriacy? International Journal of Language \& Communication Disorders 24(3). 241-263.

Blum-Kulka, Shoshana \& Elite Olshtain.1984. Requests and apologies: A crosscultural study of speech act realization patterns (CCSARP). Applied Linguistics 5(3). 196-213.

Brinton, Bonnie, Martin Fujiki, Diane Frome Loeb \& Erika Winkler. 1986. Development of conversational repair strategies in response to requests for clarification. Journal of Speech, Language, and Hearing Research 29(1). 7581.

Bruner, Jerome S. 1975. The ontogenesis of speech acts. Journal of Child Language 2(1). 1-19.

Butterworth, George \& Paul Morissette. 1996. Onset of pointing and the acquisition of language in infancy. Journal of Reproductive and Infant Psychology 14(3). 219-231.

Cameron-Faulkner, Thea. 2014. The development of speech acts. In Danielle Matthews (ed.), Pragmatic development in first language acquisition, 37-52. Amsterdam: John Benjamins.

Cameron-Faulkner, Thea, Anna Theakston, Elena Lieven \& Michael Tomasello. 2015. The relationship between infant holdout and gives, and pointing. Infancy 20(5). 576-586.

Capirci, Olga, Annarita Contaldo, Maria C. Caselli \& Virginia Volterra. 2005. From action to language through gesture: A longitudinal perspective. Gesture 5(1). 155-177.

Capirci, Olga, Jana M. Iverson, Elena Pizzuto \& Virginia Volterra. 1996. Gestures and words during the transition to two-word speech. Journal of Child Language 23(3). 645-673.

Carpenter, Malinda, Katherine Nagell, Michael Tomasello, George Butterworth and Chris Moore. 1998. Social cognition, joint attention, communicative 
competence from 9 to 15 months of age. Monographs of the Society for Research in Child Development (Serial No. 255) 63(4). 1-174.

Casillas, Marisa, Susan C. Bobb \& Eve V. Clark. 2016. Turn-taking, timing, and planning in early language acquisition. Journal of Child Language 43(6). 13101337.

Casillas, Marisa \& Michael C. Frank. 2017. The development of children's ability to track and predict turn structure in conversation. Journal of Memory and Language 92. 234-253.

Chasin, Joan \& Margaret Harris. 2008. The development of visual attention in deaf children in relation to mother's hearing status. Polish Psychological Bulletin 39(10). 1-8.

Clark, Eve V. 2009. First language acquisition. Cambridge: Cambridge University Press.

Clark, Eve V. 1973. Non-linguistic strategies and the acquisition of word meanings. Cognition 2(2). 161-182.

Clark, Herb H. 1996. Using language. Cambridge: Cambridge University Press.

Colonnesi, Cristina, Gert Jan J. M. Stams, Irene Koster \& Marc J. Noom. 2010. The relation between pointing and language development: A meta-analysis. Developmental Review 30(4). 352-366.

Csibra, Gergely \& György Gergely. 2009. Natural Pedagogy. Trends in Cognitive Sciences 13(4). 148-153.

Csibra, Gergely. 2010. Recognizing communicative intentions in infancy. Mind \& Language 25(2). 141-168.

Demuth, Katherine, Jennifer Culbertson \& Jennifer Alter. 2006. Word-minimality, epenthesis and coda licensing in the early acquisition of English. Language and Speech 49(2). 137-173.

Depowski, Nicole, Homer Abaya, John Oghalai \& Heather Bortfeld. 2015. Modality use in joint attention between hearing parents and deaf children. Frontiers in Psychology 6. 1556.

Dore, John. 1974. A pragmatic description of early language development. Journal of Psycholinguistic Research 3(4). 343-350.

Ervin-Tripp, Susan, Jiansheng Guo \& Martin Lampert. 1990. Politeness and persuasion in children's control acts. Journal of Pragmatics 14(2). 307-331.

Fernald, Anne, Virginia A. Marchman \& Adriana Weisleder. 2013. SES differences in language processing skill and vocabulary are evident at 18 months. Developmental Science 16(2). 234-248.

Fitneva, Stanka A. 2012. Beyond answers: Questions and children's learning. In Jan Peter de Ruiter (ed.), Questions: Formal, functional, and interactional perspectives, 165-178. Cambridge: Cambridge University Press.

Forrester, Michael A. 2008. The emergence of self-repair: A case study of one child during the early preschool years. Research on Language and Social Interaction 41(1). 99-128. 
Gale, Elaine \& Brenda Schick. 2009. Symbol-infused joint attention and language use in mothers with deaf and hearing toddlers. American Annals of the Deaf 153(5). 484-503.

Gaskins, Suzanne 2006. Cultural perspectives on infant-caregiver interaction. In Nicholas J. Enfield \& Stephen C. Levinson (eds.), The Roots of Human Sociality: Culture, Cognition, and Human Interaction, 279-298. Oxford: Berg.

Goodwyn, Susan W. \& Linda P. Acredolo. 1993. Symbolic gesture versus word: Is there a modality advantage for onset of symbol use? Child Development 64(3). 688-701.

Grice, H. Paul. 1975. Logic and conversation. In Peter Cole and Jerry L. Morgan (eds.), Syntax and semantics vol. 3: Speech acts, 225-242. New York: Seminar Press.

Harris, Margaret, John Clibbens, Joan Chasin \& Ruth Tibbitts. 1989. The social context of early sign language development. First Language 9(25). 81-97.

Hart, Betty \& Todd R. Risley. 1995. Meaningful differences in the everyday experience of young American children. Baltimore, MD: Paul H. Brookes Publishing.

Hilbrink, Elma E., Merideth Gattis \& Stephen C. Levinson. 2015. Early developmental changes in the timing of turn-taking: A longitudinal study. Frontiers in Psychology 6. 1492.

Holmes, Janet. 1988. Paying compliments: A sex-preferential politeness strategy. Journal of Pragmatics 12(4). 445-465.

Holzrichter, Amanda S. \& Richard P. Meier. 2000. Child-directed signing in American Sign Language. In Charlene Chamberlain, Jill P. Morford \& Rachel I. Mayberry (eds.), Language acquisition by eye, 25-40. Mahwah, NJ: Erlbaum.

Hurford, James R. 2016. Evolutionary Linguistics. In Keith Allan (ed.), The Routledge handbook of linguistics, 17-32. New York: Routledge.

Iverson, Jana M. \& Susan Goldin-Meadow. 2005. Gesture paves the way for language development. Psychological Science 16(5). 367-371.

Mitchell, Ross E. \& Michael A. Karchmer. 2004. Chasing the mythical ten percent: Parental hearing status of deaf and hard of hearing students in the United States. Sign Language Studies 4(2). 138-163.

Kaye, Kenneth \& Alan Fogel. 1980. The temporal structure of face-to-face communication between mother and infants. Developmental Psychology 16(5). 454-464.

Koester, Lynne S., Lisa R. Brooks \& Andrea M. Karkowski. 1998. A comparison of the vocal patterns of deaf and hearing mother-infant dyads during face-to-face interactions. Journal of Deaf Studies and Deaf Education 3(4). 290-301.

Lammertink, Imme, Marisa Casillas, Titia Benders, Brechtje Post \& Paula Fikkert. 2015. Dutch and English toddlers' use of linguistic cues in predicting upcoming turn transitions. Frontiers in Psychology 6. 495.

Levinson, Stephen C. 2006. On the human "interaction engine". In Nicholas J. Enfield and Stephen. C. Levinson (eds.), Roots of Human Sociality: Culture, Cognition and Interaction, 39-69. Oxford: Berg. 
Lichtert, Guido F. \& Filip T. Loncke. 2006. The development of proto-performative utterances in deaf toddlers. Journal of Speech, Language, and Hearing Research 49(3). 486-499.

Lieberman, Amy M., Marla Hatrak \& Rachel I. Mayberry. 2014. Learning to look for language: Development of joint attention in young deaf children. Language Learning and Development 10(1). 19-35.

Lieven, Elena V. M. 1994. Crosslinguistic and crosscultural aspects of language addressed to children. In Clare Gallaway \& Brian J. Richards (eds.), Input and interaction in language acquisition, 56-73. New York: Cambridge University Press.

Masataka, Nobuo. 2000. The role of modality and input in the earliest stage of language acquisition: Studies of Japanese Sign Language. In Charlene Chamberlain, Jill P. Morford \& Rachel I. Mayberry (eds.), Language acquisition by eye, 3-24. Mahwah, NJ: Erlbaum.

Meristo, Marek, Gary Morgan, Alessandra Geraci, Laura lozzi, Erland Hjelmquist, Luca Surian \& Michael Siegal. 2012. Belief attribution in deaf and hearing infants. Developmental Science 15(5). 633-640.

Moeller, Mary P. \& Brenda Schick. 2006. Relations between maternal input and theory of mind understanding in deaf children. Child Development 77(3). 751766.

Moll, Henrike, Nadja Richter, Malinda Carpenter \& Michael Tomasello. 2008. Fourteen-month-olds know what "we" have shared in a special way. Infancy 13(1). 90-101.

Moore, Richard. 2014. Ontogenetic constraints on Grice's theory of communication. In Danielle Matthews (ed.), Pragmatic development in first language acquisition, 87-104. Amsterdam: John Benjamins.

Moore, Richard, Kristin Liebal \& Michael Tomasello. 2013. Three-year-olds understand communicative intentions without language, gestures, or gaze. Interaction Studies 14(1). 62-80.

Morales, Michael, Peter Mundy, Christine E. F. Delgado, Marygrace Yale, Daniel Messinger, Rebecca Neal \& Heidi K. Schwartz. 2000. Responding to joint attention across the 6- through 24-month age period and early language acquisition. Journal of Applied Developmental Psychology 21(3). 283-298.

Morgenstern, Aliyah, Stéphanie Caët, Marie Leroy-Collombel, Fanny Limousin \& Marion Blondel. 2010. From gesture to sign and from gesture to word: Pointing in deaf and hearing children. Gesture 10(2-3). 172-202.

Mundy, Peter, Jessica Block, Christine Delgado, Yuly Pomares, Amy V. Van Hecke, \& Meaghan V. Parlade. 2007. Individual differences and the development of joint attention in infancy. Child Development 78(3). 938-954.

Murray, Lynne \& Colwyn Trevarthen. 1985. Emotional regulation of interactions between two-month-olds and their mothers. In Tiffany M. Field \& Nathan A. Fox (eds.), Social perception in infants, 177-197. Norwoord, NJ: Alex Publishing Corporation. 
Ninio, Anat, Catherine E. Snow, Barbara A. Pan \& Pamela R. Rollins. 1994. Classifying communicative acts in children's interactions. Journal of Communication Disorders 27(2). 158-187.

Ninio, Anat \& Polly Wheeler. 1984. Functions of speech in mother-infant interaction. In Lynne Feagans, Catherine Garvey \& Roberta Golinkoff (eds.), The origins and growth of communication, 196-207. Norwood, NJ: Ablex Publishing Corporation.

Ninio, Anat \& Polly Wheeler. 1986. A manual for classifying verbal communicative acts in mother-infant interaction. Transcript Analysis 3(1). 1-82.

O'Neill, Daniela K. 1996. Two-year-old children's sensitivity to a parent's knowledge state when making requests. Child Development 67(2). 659-677.

Premack, David, \& Guy Woodruff. 1978. Does the chimpanzee have a theory of mind? The Behavioral and Brain Sciences 4(1). 515-526.

Prezbindowski, Amy K., Lauren B. Adamson \& Amy R. Lederberg. 1998. Joint attention in deaf and hearing 22-month-old children and their hearing mothers. Journal of Applied Developmental Psychology 19(3). 377-387.

Pyers, Jennie E. \& Ann Senghas. 2009. Language promotes false-belief understanding evidence from learners of a new sign language. Psychological Science 20(7). 805-812.

Reddy, Vasudevi, Katja Liebal, Kerry Hicks, Srujana Jonnalagadda \& Beena Chintalapuri. 2013. The emergent practice of infant compliance: An exploration in two cultures. Developmental Psychology 49(9). 1754-1762.

Rossano, Federico. 2013. Sequence organization and timing of bonobo motherinfant interactions. Interaction Studies 14(2). 160-189.

Rossano, Federico \& Katja Liebal. 2014. "Requests" and "offers" in orangutans and human infants. In Paul Drew \& Elizabeth Couper-Kuhlen (eds.), Requesting in social interaction, 335-364. Amsterdam: John Benjamins.

Rovee, Carolyn K. \& David T. Rovee. 1969. Conjugate reinforcement of infant exploratory behavior. Journal of Experimental Child Psychology 8(1). 33-39.

Sacks, Harvey, Emmanuel A. Schegloff \& Gail Jefferson. 1974. A simplest systematics for the organization of turn-taking for conversation. Language 50(4). 696-735.

Sakkalou, Elena, Kate Ellis-Davies, Nia C. Fowler, Elma E. Hilbrink \& Merideth Gattis. 2013. Infants show stability of goal-directed imitation. Journal of Experimental Child Psychology 114(1). 1-9.

Schegloff, Emmanuel A. 2007. Sequence organization in interaction: Volume 1: A primer in Conversation Analysis. Cambridge: Cambridge University Press.

Schick, Brenda, Peter De Villiers, Jill De Villiers \& Robert Hoffmeister. 2007. Language and theory of mind: A study of deaf children. Child Development 78(2). 376-396.

Scott, Katherine, Elena Sakkalou, Kate Ellis-Davies, Elma E. Hilbrink, Ulrike Hahn \& Merideth Gattis. 2013. Infant contributions to joint attention predict vocabulary development. In Markus Knauff, Michael Pauen, Natalie Sebanz, \& Ipke 
Wachsmuth (eds.), Proceedings of the 35th annual conference of the Cognitive Science Society, 3384-3389. Austin, TX: Cognitive Society.

Searle, John R. 1969. Speech acts: An essay in the philosophy of language.

Cambridge: Cambridge University Press.

Searle, John R. 1975. What is a speech act? In Max Black (ed.), Philosophy in America. Ithaca, NY: Cornell University Press.

Searle, John R. 1976. A classification of illocutionary acts. Language in Society 5(1). 1-23.

Senju, Atsushi \& Gergely Csibra. 2008). Gaze following in human infants depends on communicative signals. Current Biology 18(9). 668-671.

Shatz, Marilyn 1978a. Children's comprehension of their mothers' questiondirectives. Journal of Child Language 5(1). 39-46.

Shatz, Marilyn 1978b. On the development of communicative understandings: An early strategy for interpreting and responding to messages. Cognitive Psychology 10(3). 271-301.

Sidnell, Jack. 2016. A conversation analytic approach to research on early childhood. In Ann Farrell, Sharon L. Kagan \& E. Kay M. Tisdall (eds.), The SAGE handbook of early childhood research, 255-276. London: SAGE publications.

Sidnell, Jack \& Tanya Stivers (eds.). 2013. The handbook of Conversation Analysis. West Sussex: Blackwell.

Snow, Catherine E. 1977. The development of conversation between mothers and babies. Journal of Child Language 4(1). 1-22.

Snow, Catherine E., Barbara A. Pan, Alison Imbens-Bailey \& Jane Herman. 1996. Learning how to say what one means: A longitudinal study of children's speech act use. Social Development 5(1). 56-84.

Spencer, Patricia E. 2000. Looking without listening: Is audition a prerequisite for normal development of visual attention during infancy? Journal of Deaf Studies and Deaf Education 5(4). 291-302.

Sperber, Dan \& Dierdre Wilson. 1986. Relevance. Cambridge: Harvard University Press.

Swisher, M. Virginia. 2000. Learning to converse: How deaf mothers support the development of attention and conversational skills in their young deaf children. In Patricia E. Spencer, Carol J. Erting \& Marc Marschark (eds.), The Deaf child in the family and at school, 21-40. Mahwah, NJ: Erlbaum.

Symons, Douglas \& Greg Moran. 1994. Responsiveness and dependency are different aspects of social contingencies: An example from mother and infant smiles. Infant Behavior and Development 17(2). 209-214.

Takada, Akira. 2012. Pre-verbal infant-caregiver interaction. In Alessandro Duranti, Elinor Ochs \& Bambi B. Schieffelin (eds.), The handbook of language socialization, 56-80. Malden, MA: Wiley-Blackwell.

Tomasello, Michael. 1995. Joint attention as social cognition. In Chris Moore, Philip J. Dunham \& Phil Dunham (eds.), Joint attention: Its origins and role in development, 103-130. Mahwah, NJ: Lawrence Erlbaum.

Tomasello, Michael. 2010. Origins of human communication. Boston, MA: MIT press. 
Tomasello, Michael, Malinda Carpenter, Josep Call, Tanya Behne \& Henrike Moll. 2005. Understanding and sharing intentions: The origins of cultural cognition. Behavioral and Brain Sciences 28(5). 687-691.

Tomasello, Michaell, Gina Conti-Ramsden \& Barbara Ewert. 1990. Young children's conversations with their mothers and fathers: Differences in breakdown and repair. Journal of Child Language 17(1). 115-130.

Volterra, Virginia \& Maria C. Caselli. 1985. From gestures and vocalization to signs and words. In William C. Stokoe \& Virginia Volterra (eds.), SLR '83

Proceedings of the III International Symposium on Sign Language Research, 1-9. Silver Spring, MD: Linstok.

Warneken, Felix \& Michael Tomasello. 2007. Helping and cooperation at 14 months of age. Infancy 11(3). 271-294.

Waxman, Robyn P. \& Patricia E. Spencer. 1997. What mothers do to support infant visual attention: Sensitivities to age and hearing status. Journal of Deaf Studies and Deaf Education 2(2). 104-114.

Weisleder, Adriana \& Anne Fernald. 2013. Talking to children matters: Early language experience strengthens processing and builds vocabulary. Psychological Science 24(11). 2143-2152.

Woodward, Amanda L. 1998. Infants selectively encode the goal object of an actor's reach. Cognition 69(1). 1-34.

Woodward, Amanda L. 1999. Infants' ability to distinguish between purposeful and non-purposeful behaviors. Infant Behavior \& Development 22(2). 145-160.

Yurovsky, Daniel. 2018. A communicative approach to early word learning. New Ideas in Psychology 50. 73-79.

Zeshan, Ulrike \& de Vos, Connie (eds.). 2012. Sign languages in village communities: Anthropological and linguistic insights. Berlin: Mouton de Gruyter. 